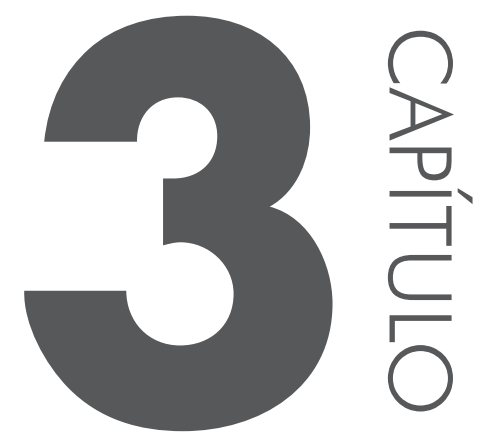

\title{
Ambiguidade estrutural e variação na concordância número-pessoa em clivadas canônicas no português brasileiro
}

Marco Antonio Martins

Francisco lokleyton de Araujo Matos

\subsection{INTRODUC̣ÃO}

Este capítulo tem uma motivação teórica e outra empírica. A motivação teórica se volta à defesa de estudos com interface entre a sociolinguística variacionista - ou a teoria da variação e mudança, que toma por objeto de estudo o fenômeno da variação linguística observada sob as lentes da noção de regra variável - e a teoria da gramática, que toma por objeto de estudo a competência do falante que sabe/fala uma língua natural. A motivação empírica deriva do contraste observado entre a possibilidade de concordância entre cópula e o SN clivado em sentenças clivadas canônicas no português brasileiro, atestada no par em (1), e a não possibilidade de variação em clivadas invertidas, como mostra o par em (2):

(1a) Foi os meninos que chegaram.

(1b) Foram os meninos que chegaram. 
(2a) Os meninos foi que chegaram.

(2b) *Os meninos foram que chegaram.

$\mathrm{Na}$ literatura sobre esse fenômeno no português brasileiro (PB), existe um consenso de que a concordância número-pessoa entre cópula "ser" e o constituinte clivado é variável nas clivadas canônicas, mas não em clivadas invertidas, como mostram Guesser e Quarezemin (2013), sob uma perspectiva formal, e Braga e Barbosa (2009), sob uma abordagem funcional. Diante desse panorama de variação e, mais especificamente, de restrição de variação descrito na literatura no que se refere às sentenças clivadas no $\mathrm{PB}$, discutimos neste capítulo, como a variação observada entre estruturas com e sem concordância nas clivadas canônicas - mas não nas clivadas invertidas - pode ser explorada no âmbito da teoria gerativa em interface com a sociolinguística laboviana, sob o escopo da noção de regra variável. Não apresentaremos aqui uma análise quantitativa dessas sentenças no $\mathrm{PB}$, mas motivaremos uma discussão que tem por objetivo esclarecer como é possível explicar essa possibilidade - ou não - de variação utilizando a teoria gerativa e uma teoria da variação linguística. O estatuto teórico dessas construções no PB tomará por base o quadro formal já posto por muitos estudos (RIZZI, 1997; MIOTO; NEGRÃO, 2007; BELLETTI, 2012; GUESSER; QUAREZEMIN, 2013).

O capítulo está assim organizado: começaremos por ilustrar o fato de que sentenças como (1) são estruturalmente ambíguas enquanto sentenças como (2) não são (seção 1); discutiremos brevemente as possibilidades de análise para a estrutura de sentenças relativas - não ambíguas em PB (seção 2); resenharemos a análise cartográfica para a estrutura das clivadas, partindo da proposta em Mioto e Negrão (2007) (seção 3); traremos uma discussão justificada pelas observações feitas nas seções anteriores que visa articular questões radicadas no campo da variação da língua, tanto do ponto de vista da teoria gerativa - que dá suporte descritivo para uma análise formal e sintática - quanto do ponto de vista da sociolinguística - teoria desenvolvida para estudar questões de variação e mudança linguística (seção 4); e encerraremos o texto com a retomada de algumas considerações feitas aqui (seção 5).

\subsection{SENTENC̣AS CLIVADAS NO PB: AMBIGUIDADE ESTRUTURAL QUE PERMITE VARIAC̣ÃO NÚMERO-PESSOA ENTRE CÓPULA E O SN CLIVADO}

Observemos que as sentenças $(1 \mathrm{a} / \mathrm{b})$ apresentadas acima podem servir como resposta às duas perguntas, respectivamente, em (3) abaixo: 
(3a) Quais meninos foram brincar?

(3b) Quem foi que chegou?

Como respostas a (3a), repetida em (4), as sentenças (1 a/b), repetidas em (5), têm uma estrutura de sentença relativa, que, conforme apresentamos com mais vagar na segunda seção deste capítulo, partilham certas propriedades estruturais específicas.

(4) Quais meninos foram brincar?

(5a) [Foi os meninos que chegaram]

(5b) [Foram os meninos que chegaram]

(5c) [Foi/foram os meninos que chegaram] que foram brincar

Por outro lado, como respostas a (3b), repetida em (6), as mesmas sentenças são estruturas clivadas, pois clivam o $\mathrm{SN}$ como resposta à pergunta. As propriedades das sentenças clivadas também são apresentadas aqui.

(6) Quem foi que chegou?

(7a) [Foi [os meninos] que chegaram].

(7b) [Foram [os meninos] que chegaram].

(7c) Foi/Foram [os meninos] que chegaram.

Podemos observar preliminarmente que, sendo clivadas, as sentenças ( $1 \mathrm{a} / \mathrm{b})$ apresentam como foco a informação nova - o constituinte ensanduichado entre cópula e o complementizador que, [os meninos]. Entretanto, sendo relativas, no constituinte [os meninos] não recai o foco de informação nova. Tal informação é parte pressuposta da sentença. Nesse caso, é em toda a sentença [que chegaram] que recai o foco e não no sintagma [os meninos].

Mioto e Negrão (2007), partindo dessa observação, apresentam fortes argumentos sintáticos, semânticos e prosódicos em favor da hipótese de que a sentença que segue o constituinte nominal de uma sentença clivada não é uma relativa.

Nas palavras dos autores, se entendemos que a prosódia é a codificação de diferenças estruturais, há um argumento prosódico favorável à hipótese. Para registrar a diferença prosódica, Mioto e Negrão realizaram um experimento que mediu o valor de pitch (acento) mais proeminente em uma mesma sentença, quando correspondia a uma clivada e quando a uma relativa. Mediram também o valor do pitch da sílaba de uma mesma palavra nos dois tipos de sentenças. Os resultados mostraram diferenças substanciais e sistemáticas, o que revelou que 
as duas sentenças devem ter estruturas sintáticas diferentes. Além da prosódia, a sintaxe e a semântica revelam diferenças significativas ${ }^{1}$.

O que queremos destacar aqui é a possibilidade de ambiguidade estrutural das sentenças clivadas canônicas em (1). Mais especificamente, queremos argumentar a favor da hipótese de que a possibilidade de variação número-pessoa na concordância entre cópula e o constituinte clivado deriva da ambiguidade estrutural das sentenças clivadas canônicas. Observe-se que essas sentenças, apesar de se realizarem linearmente iguais, podem refletir diferentes estruturas - ou clivadas canônicas ou relativas. O mesmo não se observa nas sentenças clivadas invertidas em (2), cuja única estrutura é de clivada. Nessas sentenças, a variação na concordância número-pessoa entre cópula e o SN clivado não é possível.

Uma das propriedades observadas na gramática das línguas naturais é a possibilidade, sob determinadas condições, de deslocamento de constituintes de um lugar para outro na estrutura da sentença. Em certos casos, isso resulta no que é tradicionalmente chamado de sentença relativa, clivada ou outros tipos de sentenças. Se pensarmos em termos de uma abordagem cartográfica, como propõe Rizzi (1997 e posteriores), entenderemos bem por que e para quê isso acontece. Ao olhar para a periferia esquerda da sentença e propor a cisão da categoria funcional CP, Rizzi (1997) procura dar conta da distribuição estrutural dos constituintes de periferia à esquerda da sentença. Uma das projeções de critérios postuladas por Rizzi foi a projeção FocP, que segue a rigidez hierárquica apresentada na Figura 3.1.

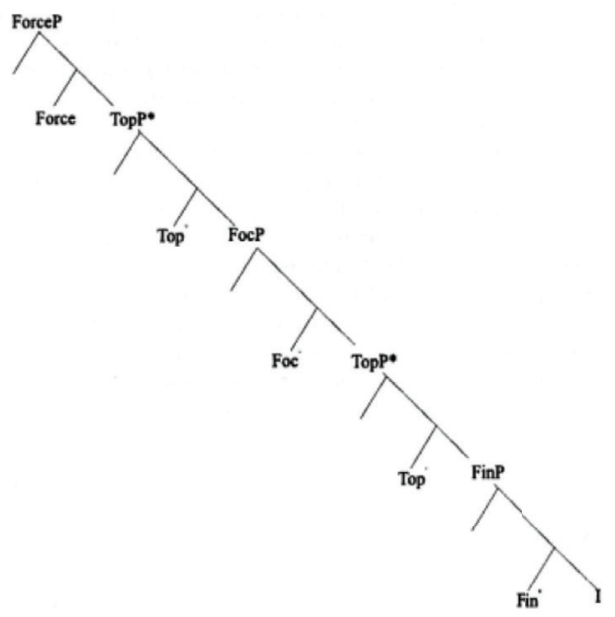

Figura 3.1 - Representação cartográfica (RIZZI, 1997, p. 297).

\footnotetext{
1 Remetemos o leitor a Mioto e Negrão (2007) para uma apreciação integral da argumentação.
} 
$\mathrm{O}$ autor defende que quando constituintes se deslocam de um lugar para outro na sentença, eles o fazem para atender a determinados requerimentos de critérios específicos. Um constituinte com traço [+foco], por exemplo, pode ser gerado em uma determinada posição (argumento interno ou externo de um núcleo lexical) e se mover para o especificador de um núcleo funcional - do núcleo Foc, por exemplo -, a fim de satisfazer tal requerimento gramatical, isto é, ser interpretado como constituinte focalizado na sentença.

Temos uma sentença clivada quando estamos diante de uma estrutura complexa com a seguinte configuração:

(8) CÓPULA + [XP] + [CP]

Nessa configuração, [CP] veicula uma informação pressuposta e o [XP] representa um elemento focalizado, como observamos em (9):

\section{FOCO}

(9) Foi [o telefone] que a Maria perdeu.

\section{CÓPULACP}

É importante mencionar, ainda, as sentenças denominadas pseudoclivadas (10). Embora tenham em comum a propriedade de focalizar o constituinte pós cópula, se diferenciam por algumas especificidades. Esse tipo de sentença apresenta como sujeito uma relativa livre introduzida por uma expressão $\mathrm{WH}$.

(10) O que Beatriz comprou foi [um tênis].

De acordo com Mioto e Negrão (2007), e de maneira bastante resumida, as diferenças entre as clivadas e as pseudoclivadas são: (i) o fato de as clivadas apresentarem um que preenchendo o $\mathrm{CP}$ e as pseudoclivadas uma expressão WH, que pode ser omitida; (ii) semanticamente, as pseudoclivadas podem ser especificacionais ou predicacionais, enquanto as clivadas só podem ser especificacionais; e (iii) há restrições quanto ao tipo de foco que clivadas e pseudoclivadas realizam.

Voltemo-nos à estrutura das sentenças clivadas em PB.

\subsubsection{UMA ANÁLISE CARTOGRÁFICA DAS SENTENÇAS CLIVADAS}

Assumimos a proposta de Mioto e Negrão (2007) para a estrutura das clivadas no $\mathrm{PB}$, refinando-a a partir da abordagem cartográfica, como propõem Guesser e Quarezemin (2013), que, por sua vez, seguem os trabalhos de Roisenberg e Menuzzi (2008) e de Belletti (2012). 
Com base em considerações acerca de outras análises para a estrutura das clivadas, Mioto e Negrão (2007) propõem a seguinte estrutura para as sentenças clivadas canônicas:

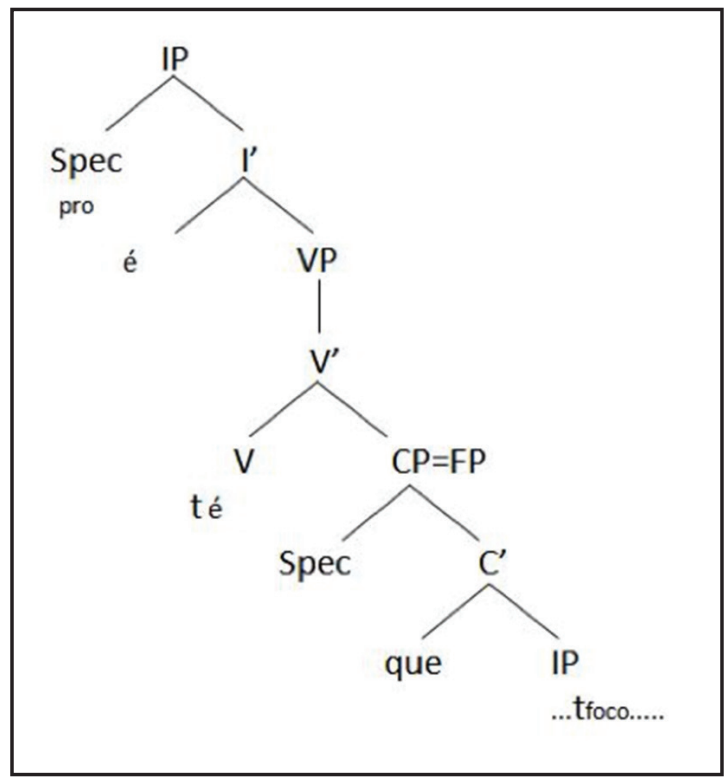

Figura 3.2 - Estrưura das sentenças clivadas canônicas (MIOTO; NEGRÃ0, 2007, p. 174).

Os autores consideram na formalização da proposta a estrutura do sistema complementizador de Rizzi $(1997 ; 2001)$ e também a hipótese de Belletti (2012), segundo a qual se a clivada é canônica e o elemento focalizado é o sujeito, o CP complementizador da cópula contém um traço EPP, que exprime uma relação de predicação entre o sujeito em CP e a sentença que segue. Sendo assim, propõem um refinamento da estrutura de modo a ter a seguinte configuração para sentenças clivadas canônicas no PB:

(11a) Foi [um rapaz] que comeu a torta.

(11b) proexpl... [TP foi j [VP ..... tj [FocP um rapaz i [EPP ti... ... [ FinP que [TP comeu ti a torta]]]]

Seguindo a proposta de Belletti (2012), Guesser e Quarezemin (2013) analisam as clivadas invertidas no $\mathrm{PB}$ por meio do processo de extraposição de FinP. $\mathrm{Na}$ proposta das autoras, a extraposição funciona como a solução que viabiliza o movimento do constituinte talhado como foco para a posição de foco da sentença matriz, sem que isso acarrete violação do princípio do congelamento criterial (cf. RIZZI, 2012, p. 130), cuja predição está em (12). 

nele. $^{2}$

(12) Congelamento Criterial: um XP encontrando um critério fica congelado

Dessa maneira, a extraposição explica como pode o constituinte focalizado estar na periferia esquerda da sentença matriz, e não na periferia esquerda da sentença onde ele é gerado (sentença encaixada), sem que haja violação do princípio de congelamento criterial.

A estrutura das clivadas invertidas em PB segue a derivação, cujas operações são dadas passo a passo abaixo - exemplificada considerando a sentença em (13) -, como mostram Guesser e Quarezemin (2013) para clivadas com foco contrastivo no PB:

(13) Os meninos foi que a Maria encontrou (não as meninas).

(14a) Movimento do sintagma [+foco] para o Spec de FocP encaixado:

[CP [FocP [TP foij ... [vP tj [FocP os meninos...[ FinP que [TP a Maria encontrou - ]]]

(14b) Extraposição do FinP subordinado:

[CP[FocP [TP... foij [vP tj [FocP os meninos... ] [ FinP que [TP a Maria encontrou - ]

(14c) Movimento da projeção de FocP encaixada para a periferia esquerda da frase matriz:

[CP[FocP [FocP os meninos ... ] [TP foi ...[vP tj [] [ FinP que [TP a Maria encontrou - ]

Mesmo sendo satisfatória para explicar muito sobre o comportamento sintático das sentenças clivadas no PB, tal análise para as clivadas invertidas esbarra no problema de conseguir dar conta de uma explicação sintática para o fato de ser possível a concordância da cópula com o foco em clivadas canônicas, mesmo o foco ocupando uma posição A'. E esse ponto é particularmente importante para a discussão que queremos fazer neste capítulo, pois toca na questão de como essa variação pode ser abordada e explicada.

Guesser e Quarezemin (2013) explicam o duplo padrão de concordância nas clivadas canônicas assumindo que, quando AGR é projetado, o XP [+foco] transita no seu Spec antes de ir a FocP e, como consequência, manifesta uma relação de concordância com AGR, como vemos na Figura 3.3.

\footnotetext{
2 Tradução livre do original: Criterial Freezing - an XP meeting a Criterion is frozen in place.
} 
a. $T$... ser [CP Foree FocP os meninos ${ }_{i}$ Foc ... [AGR $t_{i}\left[\right.$ FinP que [TP chegaram $\left.\left.\left.t_{i}\right]\right]\right]$

\author{
Agree \\ b. T...foram [CP Fore FocP os meninos ${ }_{i}$ Foc ... [AGR $t_{i}$ [FinP que [TP chegaram $t_{i}$ ] ]]]
}

Figura 3.3 - Representação de padrão de concordância (GUESSER; QUAREZEMIN, 2013, p. 203).

Segundo as autoras, nas clivadas invertidas a cópula não entra em relação de concordância com o foco porque o processo de extraposição inviabiliza esse procedimento. No entanto, a análise não explica em que medida a extraposição destrói essa possibilidade, ponto que requer, ainda, uma explicação.

Buscamos nesta seção suscitar algumas considerações acerca da estrutura das clivadas canônicas e invertidas no $\mathrm{PB}$, tendo em vista o duplo padrão de concordância entre cópula e o constituinte focalizado. Do dito, podemos dizer que, independente de qual modelo adotemos para analisar as relativas - cujas propostas serão retomadas na seção seguinte -, clivadas e relativas devem ter estruturas sintáticas distintas. No que segue, indicaremos como as sentenças relativas são analisadas na literatura gerativista, sem deixar de lado o fato de que encontramos variação nesse tipo de sentença, o que nos leva a apresentar um breve panorama de pesquisas já realizadas a partir de estudos variacionistas.

\title{
3.3 SENTENÇAS RELATIVAS NO PB
}

A intuição que se tem sobre o que seja uma sentença relativa pode ser formalizada da seguinte maneira, segundo De Vries (2002 apud MIOTO; NEGRÃO, 2007):

(i) É uma sentença encaixada.

(ii) É conectada ao material circundante por um constituinte que funciona como pivô. O pivô é um constituinte semanticamente partilhado pela matriz e pela relativa. Se o pivô, normalmente um sintagma nominal, é realizado na sentença matriz, ele é reconhecido como um antecedente.

(iii) O papel temático e a função sintática que o constituinte pivô desempenha na sentença relativa são em princípio independentes de seu papel semântico e de sua função sintática fora da relativa.

Dessa maneira, quando analisamos sentenças do português como aquelas exemplificadas em (15), não temos dúvida sobre o fato de as sentenças entre colchetes serem relativas. 
(15a) A Beatriz jantou com os candidatos [que ganharam a eleição].

(15b) O Carlos perdeu o caderno [que a mãe comprou].

(15c) Eu nunca vou esquecer [o que aquela pessoa fez comigo].

As sentenças destacadas apresentam em comum exatamente as propriedades sintáticas e semânticas listadas acima: $\operatorname{Em}(15 \mathrm{a} / \mathrm{b})$, os constituintes [os candidatos] e [o caderno] funcionam como pivô, conectando as duas sentenças; já em (15c), temos o que a literatura considera como uma relativa livre, caracterizada por apresentar uma expressão WH, que pode ser entendida como interna ou externa à relativa.

Agora, sentenças como (1), retomadas em (16) a seguir, são ambíguas, podendo ser relativas ou clivadas canônicas:

(16a) Foi os meninos que chegaram.

(16b) Foram os meninos que chegaram.

$\mathrm{Na}$ seção anterior, apresentamos algumas análises para a estrutura das clivadas em PB. Apresentamos a seguir análises para as sentenças relativas.

\subsubsection{ANÁLISE ESTRUTURAL PARA AS RELATIVAS³}

Existem pelo menos duas propostas distintas para a estrutura das sentenças relativas: a proposta segundo o modelo wh-moviment e a proposta do modelo raising. Chomsky (1977) propõe que o processo de relativização estaria instanciado no que ele apresenta como o fenômeno geral das regras de movimento wh. De acordo com essa análise, a sentença relativa entra em processo de adjunção com o DP pivô da sentença matriz, como representado em (17).

(17) relativização = adjunção de CP a DP

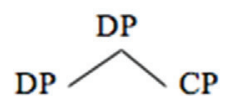

3 Ver Kenedy (2014) para uma discussão mais detalhada dessas propostas. 
Seguindo o modelo raising, Kayne (1994) sugere que as relativas não deveriam ser analisadas como adjunto de DP, mas como complementos de um núcleo determinante D. Uma das motivações para tal análise seria a adequação ao axioma de correspondência linear (LCA, do inglês Linear Correspondence Axiom). Sendo assim, teríamos resumidamente uma estrutura como (18).

(18) relativização = complementação de $\mathrm{CP}$ a D

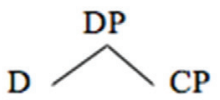

Nosso objetivo aqui não é argumentar a favor de uma ou outra proposta, mas apenas revisar o que é apresentado na literatura, de maneira bastante resumida, como explicação sintática para a estrutura das sentenças relativas, a fim de podermos comparar esse tipo de sentença com as clivadas canônicas em termos de estrutura.

\subsubsection{UM BREVE PANORAMA DA VARIAÇÃO NAS SENTENÇAS RELATIVAS DO PORTUGUÊS CULTO FALADO NO BRASIL}

Na seção anterior, fizemos uma revisão bastante abreviada do que vem sendo apresentado em pesquisas de orientação formal, a respeito de uma explicação sintática para a derivação das sentenças relativas. Um fato que, inevitavelmente, nos chama a atenção é a variação nas relativas com núcleo nominal em que temos em jogo um PP. Tarallo, em seu trabalho clássico na década de 1980 sobre estratégias de relativização no $\mathrm{PB}$, mostra que, além da relativa denominada padrão (o homem a que me referi é muito bom) e da relativa cortadora (o homem que me referi é muito bom), no século XIX já havia registro de uma forma inovadora, a relativa com pronome lembrete (o homem que me referi a ele é muito bom). Trabalhos posteriores, como o de Braga, Kato e Mioto (2009), mostram variação a partir do corpus do Projeto da Norma Urbana Oral Culta NURC e apresentam resultados que realçam o quanto a estrutura linguística está relacionada à estrutura social, no que diz respeito à variação.

Braga, Kato e Mioto (2009) atestam que as relativas com pronomes lembretes apresentam uma frequência muito baixa. $\mathrm{Na}$ amostra analisada pelos autores, foram encontradas dez relativas com pronome lembrete em 701 dados. Com isso, foi possível prognosticar que a escolarização atuaria diretamente na produção 
de relativas sem resumptivo. O corpus do NURC, então, mostrou-se bastante adequado para estudar variação entre a relativa padrão e a relativa cortadora.

Os resultados obtidos e apresentados em Braga, Kato e Mioto (2009), após um refinamento da análise para observar a estratégia de relativização usada com maior frequência por falantes escolarizados, está sintetizado na Tabela 3.1, que mostra como se distribuem as relativas que têm e as que não têm preposição na periferia esquerda por função sintática.

\begin{tabular}{|c|c|c|c|c|c|}
\hline \multirow[t]{2}{*}{ Função sintática } & \multicolumn{2}{|c|}{ Com } & \multicolumn{2}{|c|}{ Sem } & \multirow[b]{2}{*}{ Total } \\
\hline & $\mathrm{N}^{\circ}$ & $\%$ & $\mathrm{~N}^{\circ}$ & $\%$ & \\
\hline Adjunto adverbial & 35 & 49 & 37 & 51 & 72 \\
\hline Objeto indireto & 6 & 23 & 20 & 77 & 23 \\
\hline Complemento nominal & 2 & 15 & 11 & 85 & 13 \\
\hline Complemento adverbial & $*$ & * & 5 & 100 & 5 \\
\hline Genitivo & $*$ & * & 7 & 100 & 7 \\
\hline Total & 43 & 35 & 80 & 65 & 123 \\
\hline
\end{tabular}

Tabela 3.1 - Distribuição dos PP relativizados com e sem preposição por função sintática (BRAGA; KATO; MIOTO, 2009, p. 251).

Além de terem observado que o grau de escolarização se relacionava diretamente com a variação das relativas, uma vez que a frequência de resumptivas foi mínima no corpus - o que não acontece em trabalhos que analisam a fala de informantes menos escolarizados -, os autores puderam diagnosticar que um forte condicionador linguístico para a retenção ou apagamento da preposição é a função sintática do constituinte nucleado pela preposição. Isso porque as preposições núcleos de adjuntos são lexicais, isto é, apresentam importe semântico e S-selecionam seu argumento. Nas demais funções sintáticas, as preposições são funcionais e, portanto, não apresentam importe semântico, apenas C-selecionam seu argumento. Sendo assim, o apagamento de uma preposição lexical poderia em alguns casos ocasionar danos à interpretação semântica da sentença.

Nesta seção apresentamos como é possível analisar em termos de estrutura sintática as sentenças relativas e muito brevemente a variação nelas atestadas no PB. É importante dizer que nesse tipo de sentença há variação, mas que não gera ambiguidade estrutural. Uma relativa é sempre uma relativa, o que não acontece com as clivadas canônicas que podem apresentar uma estrutura de relativa ou uma estrutura de clivada. 


\subsection{EM DEFESA DA SOCIOLINGUÍSTICA EM INTERFACE COM A TEORIA GERATIVA: A AMBIGUIDADE ESTRUTURAL COMO MOTIVADORA DA VARIAC̣ÃO DE NÚMERO-PESSOA ENTRE CÓPULA E SN CLIVADO NAS SENTENC̣AS CLIVADAS CANÔNICAS NO PB}

Quando apresentamos, nas seções anteriores, discussões estritamente sintáticas sobre as estruturas das sentenças clivadas e relativas no $\mathrm{PB}$, fizemos isso aprovisionados por uma teoria naturalística da linguagem humana - a teoria chomskiana. Nessa perspectiva, concebe-se a ciência da linguagem como "uma teoria computacional do sistema 'na cabeça' [do indivíduo] como uma versão abstrata da biologia (essencialmente como uma Língua- $\mathrm{I}^{4}$ )" (CHOMSKY, 2014, p. 259).

A noção de Língua-I (individual, interna, intensional, inata, intrínseca) exige da teoria métodos de investigação das ciências naturais, tal como o lançamento de hipóteses apoiadas natural e empiricamente em relação à natureza de seu objeto de pesquisa, que é a Língua-I. Tal proposta não nega a existência de uma língua em uso (aquela que é Externalizada). Muito pelo contrário. Para que se possa chegar a uma teoria da Língua-I do indivíduo, o pesquisador parte, inevitavelmente, de dados da Língua-E. No entanto, mesmo tendo a obrigação com o epifenômeno que é a Língua-E, a teoria não se compromete com o fato de indivíduos variarem movidos por fatores sociais e estilísticos quanto ao uso de determinadas estruturas sintática, como é o caso das clivadas (foi os meninos que chegaram $x$ foram os meninos que chegaram, por exemplo). Provavelmente isso não é de interesse de uma teoria naturalística, já que as motivações para fatos como esse não são de ordem natural, mas possivelmente envolvem fatores convencionais, sociais ou idiossincráticos.

Isso não quer dizer que a variação entre as línguas ou a variação em uma mesma língua de uma determinada comunidade de fala, comunidade de práticas ou rede social seja algo banal ou desprovido de teorização. Muito pelo contrário, a sociolinguística variacionista propõe-se como uma teoria sobre a variação

\footnotetext{
4 Utilizamos as noções Língua-I e língua-E para distinguir, conforme propõe Chosmsky (2014, p. 257-258), duas instanciações distintas relacionadas ao estudo da linguagem. Entende-se Língua-I como uma instanciação biológica, radicada na nossa mente/cérebro, e completamente independente do ambiente em que o indivíduo se insere, portanto interna e individual. Língua-E, por outro lado, é o produto/manifestação concreto e público de uma língua, que se apresenta por meio de linguagem, objeto social dependente do ambiente ou da comunidade.
} 
e a mudança nas línguas, e avalia em que medida fatores linguísticos, sociais, convencionais ou idiossincráticos atuam.

Temos aqui dois aportes teóricos que diferem quanto ao objeto de investigação: enquanto para um importa um sistema mental que tem a competência de gerar uma língua natural potencialmente infinita a partir de procedimentos finitos e recursivos; para o outro, importa o que está por trás da variação - ou por trás do que condiciona a variação e consequentemente a mudança linguística - observada em uma determinada língua/comunidade de fala. Como resultado, temos uma ciência de viés puramente naturalístico e outra de viés social.

Entretanto, nada nos impede de propor um estudo que utilize contribuições teórico-metodológicas das duas perspectivas teóricas. Muito pelo contrário. No Brasil, tal articulação teórica encontrou um terreno fértil e muitos fenômenos foram descritos e explicados nessa perspectiva, tendo em vista o português brasileiro em oposição ao Português Europeu ${ }^{5}$, ainda mais se considerarmos o caráter teórico dependente da Sociolinguística Variacionista que, por natureza, necessita estar em interface com uma ou outra teoria linguística, sob pena de limitar-se à simples contagem de ocorrências, conforme aponta Freitag (2009).

Voltemo-nos à possibilidade/não possibilidade de variação na concordância número-pessoal entre a cópula e o constituinte clivado nas sentenças clivadas canônica e invertida no PB. Tendo em vista que a estrutura postulada para as sentenças clivadas acomoda sem complicações um padrão de não concordância da cópula com o constituinte focalizado, já que este se encontra deslocado para uma posição A', sugerimos, por hipótese, que a gramática passou a possibilitar um segundo padrão - padrão de concordância -, ocasionado pela ambiguidade estrutural dessas sentenças - que podem ser clivadas ou relativas. Observe que essa variação seria, nesse caso, uma possibilidade gerada pela gramática da língua, em termos de competência linguística.

Supomos, ainda, que, com a reanálise, padrões distintos disponibilizados pela gramática do PB passaram a co-ocorrer, de modo que temos, nesse caso, uma possibilidade de investigação - ainda a ser realizada! - que verifique empiricamente a associação entre grau de escolarização e distintos padrões sintáticos, alvos da aplicação da regra variável sociolinguística.

A seguir, discutiremos fatos relacionados à origem da mudança como propõe a Teoria Gerativa e apresentaremos a noção de regra variável assim como concebida pela sociolinguística variacionista. Nosso objetivo é mostrar como a Teoria Gerativa pode explicar a variação na gramática, e como a Sociolinguística

\footnotetext{
5 Remetemos o leitor a Martins, Coelho e Cavalcante (2015) para um panorama do enquadramento teórico da sociolinguística variacionista em interface com a teoria gerativa.
} 
pode explicar a variação no sistema (na comunidade) (MARTINS; COELHO; CAVALCANTE, 2015).

\subsubsection{JUSTIFICANDO/ADEQUANDO A ANÁLISE DA VARIAÇÃO NAS CLIVADAS CANÔNICAS EM UMA PROPOSTA DE INTERFACE}

Assim como nos demais componentes da gramática - fonológico, morfológico, lexical, semântico, discursivo (cf. COELHO et al., 2014) -, no componente sintático, podemos verificar variação, desde que seja possível aplicar, como propõe Labov (1978), aquela que é uma noção basilar da sociolinguística, a noção de regra variável'

Podemos, sem muito esforço, considerar como um fenômeno variável a concordância número-pessoa entre a cópula e o foco de sentenças clivadas do $\mathrm{PB}$, sugerindo, nesse caso, que fatores linguísticos e extralinguísticos possam estar envolvidos no condicionamento da variação, além do fato de constatarmos que os diferentes padrões de concordância não alteram o significado representacional da estrutura em um mesmo contexto.

Nesse caso, seria imprescindível ao pesquisador, para o estudo/descrição/ explicação da variação, ter o controle das condições relacionadas com a estrutura linguística, tais como a natureza sintática do elemento focalizado (se sujeito, objeto etc.), a natureza discursiva do elemento focalizado (se foco de nova informação ou foco contrastivo), entre outras diferenciações que possam se fazer relevantes para a manutenção do significado da estrutura em um mesmo contexto.

Uma grande contribuição evidenciada por estudos de interface entre a Teoria da Variação e Mudança e a Teoria Gerativa diz respeito ao problema da implementação (cf. WEINREICH; LABOV; HERZOG, 2006) que está fortemente relacionado com a origem e a propagação da mudança. Martins (2013), centrando sua argumentação no estatuto diferenciado que o problema de implementação tem em uma ou outra teoria, defende que o estudo da mudança sob o escopo do modelo de competição de gramáticas consegue um alinhamento teórico entre a Teoria da Variação e Mudança e a Teoria Gerativa na medida em que alcança padrões de explicação do fenômeno linguístico e a causa da mudança como uma diferenciação estrutural na gramática de um língua natural e a propagação da mudança no contínuo diacrônico.

\footnotetext{
${ }^{6}$ Não vamos retomar aqui a discussão entre Labov (1978) e Lavandera (1978) motivada pelo trabalho sobre as passivas do inglês de Weiner e Labov (1983). Entendemos que essa discussão está datada e não se justifica depois de inúmeros estudos e resultados obtidos tendo em vista estudos sobre fenômenos sintáticos em variação e mudança, desenvolvidos sobretudo no Brasil.
} 
Em termos do que propõe Lightfoot (1991), a respeito de como surge a mudança na sintaxe, podemos entender, seguindo a proposta da Teoria Gerativa, que a mudança sintática surge quando acontece uma mudança gramatical em que a criança reinterpreta de modo errado a marcação paramétrica da língua alvo, considerando os dados linguísticos primários. Essa reanálise de partes dos dados linguísticos primários pode ter como causa a ambiguidade estrutural de dados linguísticos primários ${ }^{7}$ na expressão de um dado valor paramétrico.

Em relação ao fenômeno em variação aqui em tela - a concordância entre cópula e o elemento clivado nas clivadas canônicas -, podemos aventar a hipótese de que, diante do fato de termos ambiguidade estrutural envolvendo construções relativas e construções clivadas na gramática do $\mathrm{PB}$ - construções que se distinguem do ponto de vista sintático/estrutural, conforme bem discutido em Mioto e Negrão (2007) e brevemente revisitado aqui - temos aí uma situação desencadeadora de variação e consequentemente de mudança gramatical. Em outras palavras, diante da possibilidade de a gramática licenciar um padrão inovador, tendo em vista a ambiguidade estrutural (sentenças com concordância cópula-foco), podemos observar variação no sistema (comunidade).

Se uma sentença como (1a), repetida a seguir em (22a), pode ser estruturalmente ambígua - ou clivada ou relativa -, mas não (2a), repetida a seguir em (23a), temos razão para entender por que pode haver variação quanto à concordância da cópula com o foco quando a sentença for uma clivada canônica, mas não quando for uma clivada invertida (como mostra a sentença mal formada em $(23 b))$, já que a inversão elimina a possibilidade de ambiguidade.

(19a) Foi os meninos que chegaram.

(19b) Foram os meninos que chegaram.

(20a) Os meninos foi que chegaram.

$(20 \mathrm{~b})$ *Os meninos foram que chegaram.

Conforme já mostrado, as sentenças (19 a/b) e (20a) poderiam vir como resposta, respectivamente, às seguintes perguntas:

\footnotetext{
7 Entendemos por "dados linguísticos primários" toda e qualquer performance linguística que serve como input ao qual a criança é exposta quando está adquirindo sua língua. O conhecimento que a criança traz internamente, representado pela Teoria da Gramática Universal (GU), associado aos dados linguísticos primários, vai resultar em um estágio final de língua (cf. CHOMSKY, 1965). Sendo assim, a linguagem é resultado da interação de dois diferentes fatores, quais sejam, o estado inicial e o curso da experiência. Nas palavras de Chomsky, "podemos conceber o estado inicial como um 'sistema de aquisição da linguagem', que toma a experiência como input e fornece a linguagem como ouput - um ouput que é internamente representado na mente/cérebro" (CHOMSKY, 2005, p. 31).
} 
(21) Quem foi que chegou?

(22) Quais meninos pediram lanche?

Uma vez que servem de resposta a (21), as sentenças em (19) podem apresentar uma estrutura de sentença clivada, em que o constituinte [os meninos] ocupa posição de foco de informação nova (e não contrastivo), uma posição criterial em termos de Rizzi (1997). Mas podem também responder a uma pergunta como (25), o que desencadearia, em termos representacionais, uma outra estrutura, na qual o constituinte [os meninos] não seria o foco, inclusive fazendo parte da informação já dada no discurso, e teríamos, então, uma sentença relativa com o constituinte [os meninos] como pivô e o que não como um complementizador, mas como pronome relativo. Seria uma sentença relativa, portanto.

Tais fatos, abordados sob a perspectiva de um modelo formal, nos levam à possibilidade de uma análise de variação na sintaxe do PB. Essa análise, como vemos, pode se constituir em um estudo que utilize contribuições de duas propostas teóricas, quais sejam: a Sociolinguística Variacionista e Teoria Gerativa. De volta ao problema da implementação, consideremos que, para Weinreich, Labov e Herzog (2006), esse problema está relacionado fortemente à origem e à propagação da mudança. E enquanto a Teoria Gerativa propõe uma boa explicação para a origem, a Sociolinguística Variacionista deixa sua grande contribuição ao explicar a propagação de um processo de mudança, mostrando como este se implementa na estrutura linguística e social de uma comunidade de fala. Como já dito aqui, tais estudos têm ganhado fôlego quando a mudança é estudada via modelo de competição de gramáticas, que, nas palavras de Martins,

tem se mostrado um campo fértil para o estudo da origem, no quadro teórico da Gramática Gerativa, e da propagação, no quadro teórico da Sociolinguística Variacionista, da mudança sintática. Abre-se, nesse sentido, um campo fértil de trabalho em busca de respostas aos problemas empíricos de encaixamento e propagação no estudo da mudança sintática (2013, p. 21).

\subsection{CONSIDERAC̣ÕES FINAIS}

Neste capítulo, defendemos uma base teórica para o estudo da variação sintática, amparada na interface entre a Teoria da Variação e Mudança e a Teoria Gerativa. A motivação empírica é o contraste observado na possibilidade ou não de concordância entre cópula e SN clivado em sentenças clivadas canônicas e 
clivadas invertidas no português brasileiro $(\mathrm{PB})$. Defendemos que a variabilidade na marcação da concordância nas clivadas canônicas é gerada pela ambiguidade estrutural envolvendo tais construções, que podem ser relativas ou clivadas, diferentemente das clivadas invertidas que só podem estar associadas a uma estrutura de clivada. Mais especificamente, mostramos que sentenças clivadas podem ser estruturalmente ambíguas e de que maneira isso pode estar relacionado com a origem da variação e mudança na sintaxe.

Toda a descrição empírica e teórica apresentada aqui mereceria uma discussão pormenorizada e aprofundada que não coube para este momento. Nosso objetivo foi suscitar algumas questões teóricas que podem ser tomadas como alicerce para pesquisas empíricas variacionistas em conexão com uma teoria linguística de base formal que podem ser realizadas no futuro.

\subsection{REFERÊNCIAS}

BELLETTI, A. Revisiting the CP of clefts. In: GREWENDORF, G.; ZIMMERMANN, T. E. (Ed.). Discourse and Grammar: from sentence types to lexical categories. Berlin: Walter de Gruyter Inc, 2012. p. 91-114.

BRAGA, M. L.; BARBOSA, E. de M. Construções clivadas no português brasileiro sob uma abordagem funcionalista. Matraga, Rio de Janeiro, v. 16, p. 173-196, 2009.

BRAGA, M. L.; KATO, M. A.; MIOTO, C. As construções qu- no Português Brasileiro falado: relativas, clivadas e interrogativas. In: CASTILHO, A.; KATO, M. A.; NASCIMENTO, M. (Org.). Gramática do Português Culto Falado. v. III. Campinas: Editora da Unicamp, 2009, p. 241-294.

CHOMSKY, N. Aspects of the Theory of Syntax. Cambridge: MIT Press, 1965 .

. On Wh-Movement. In: CULICOVER, P.; WASOW, T.; AKMAJIAN, A. (Ed.). Formal syntax. Nova York: Academic Press, 1977. p. 71-132.

. Novos Horizontes no estudo da linguagem e da mente. Tradução de Marco Antônio Sant'Anna. São Paulo: Editora Unesp, 2005.

. A ciência da linguagem: conversas com James McGilvray. Tradução de Gabriel de Ávila Othero, Luisandro Mendes Souza, Sérgio de Moura Menuzzi. São Paulo: Editora Unesp, 2014.

COELHO, I. L. et al. Para conhecer sociolinguística. São Paulo: Contexto, 2015.

FREITAG, R. M. KO. Problemas teórico-metodológicos para o estudo da variação linguística nos níveis gramaticais mais altos. Matraga, Rio de Janeiro, v. 16, p. 115-132, 2009. 
GUESSER, S. L.; QUAREZEMIN, S. Focalização, cartografia e sentenças clivadas do Português Brasileiro. Linguística, Rio de Janeiro, v. 9, n. 1, p. 13, 2013.

KAYNE, R. S. The antisymmetry of syntax. Cambridge: The MIT Press, 1994.

KENEDY, E. Estruturas sintáticas de orações relativas. In: BISPO, E. B.; OLIVEIRA, M. R. (Org.). Orações relativas do português brasileiro: diferentes perspectivas. Niterói: EDUFF, 2014. p. 11-46.

LABOV, W. Where does the linguistic variable stop? A response to Beatriz Lavandera. Sociolinguistic Working Paper, n. 44, p. 43-88, 1978.

LAVANDERA, B. Where does the linguistic variable stop? Language Society, Cambridge, n. 7, p. 171-182, 1978.

LIGHTFOOT, D. How to set parameters: arguments from language change. Cambridge: MIT Press, 1991.

MARTINS, M. A. Gramática ou gramáticas do Português Brasileiro? O problema da implementação na mudança sintática. Línguas e Instrumentos Linguísticos, Campinas, v. 32, p. 9-27, 2013.

MARTINS, M. A.; COELHO, I. L.; CAVALCANTE, S. R. de O. Variação sintática e Teoria Gerativa. In: MARTINS, M. A.; ABRAÇADO, J. (Org.). Mapeamento sociolinguístico do português brasileiro. São Paulo: Contexto: 2015. p. 221-247.

MIOTO, C.; NEGRÃO E. As sentenças clivadas não contêm uma relativa. In: CASTILHO, A. T. et al. (Org.). Descrição, história e aquisição do português brasileiro. São Paulo; Campinas: FAPESP; Pontes, 2007. p. 159-186.

RIZZI, L. The fine structure of the left periphery. In: HAEGEMAN, L (Ed.). Elements of Grammar. Kluwer: Dordrecht, 1997. p. 281-337.

. On the position of interrogative in the left periphery of the clause. In: CINQUE, G.; SALVI, G. P. (Ed.). Current studies in Italian syntax. Essays Offeredto Lorenzo Renzi, Oxford: Elsevier North-H, 2001. p. 287-296.

. Delimitation effects and the cartography of the left periphery. In: GREWENDORF, G.; ZIMMERMANN, T. E. (Ed.). Discourse and Grammar: from sentence types to lexical categories. Berlin: Walter de Gruyter Inc, 2012. p. 115-146.

ROISENBERG, G.; MENUZZI, S. Pressuposição, exaustividade e denegação nas clivadas. In: ENCONTRO DO CELSUL. Porto Alegre: Universidade Federal do Rio Grande do Sul, 2008. Disponível em: http://www.geocities.ws/smenuzzi/ download/exaustividade_celsul_2008.pdf Acesso em: 27 mar. 2016.

WEINER, J.; LABOV, W. Constrains on the agentless passive. Journal of Linguistics, Cambridge, v. 19, n. 1, p. 29-58, 1983. 
WEINREICH, U.; LABOV, W.; HERZOG, M. Fundamentos empíricos para uma teoria da mudança linguística. Tradução de Marcos Bagno. São Paulo: Parábola, 2006. 
